\title{
Pluralism and the Unity of Science
}

Angela Breitenbach and Yoon Choi

\begin{abstract}
This essay argues for a conception of the unity of science that is of distant but distinct Kantian provenance. We first review some of the challenges that undermined two influential predecessor conceptions of the unity of science. Many of these criticisms were raised by pluralists, who found them reason enough to embrace the disunity of science. We propose an alternative response. We argue that the epistemic advantages of pluralism arise only when it is combined with a limiting constraint: when it is what we call unified pluralism. Moreover, once we accept unified pluralism, an ideal emerges of a pluralist unity of science. We argue that we have good reason to adopt this ideal as regulative of scientific inquiry, and as guiding discovery of the laws of nature when and where they exist.
\end{abstract}

\section{Introduction}

In this essay, we set out and defend an argument for the unity of science. ${ }^{1}$ Philosophical discussions of the unity of science have a long and distinguished history, and they have generally been accompanied by celebratory visions of the elegant order, harmony, and lawfulness of nature. Challenges to this tradition-arguments that do not just reconcile us to, but positively celebrate the disunity or pluralism of science-have come with their own companion views of nature, whether it appears "dappled," with local pockets of order and lawfulness jostling against each other in an unruly way (Cartwright 1999), or downright lawless, an exuberant and untamable variety (Dupré 1993).

\footnotetext{
${ }^{1}$ We understand 'science' in the broadest sense, to include all sciences—not just the natural sciences.
} 
Our aim in this paper is to re-visit this debate with the intention of proposing an alternative conception of the unity of science. Our view takes off from Kant's idea that the unity of science is a necessary but merely regulative ideal, one that should guide scientific inquiry. ${ }^{2}$ This ideal is one of complete comprehensibility, of a science that makes the world understandable to us as a whole. It is thus grounded not in the metaphysics of nature, but in our epistemic nature. This means that the unity of science is not dependent on the universality and fundamentality of the laws of nature, but allows instead for the discovery of irreducible variety and lawlessness in nature. It may turn out that some parts of science champion heterogeneous and irreducible laws, and that others are not engaged in the discovery of laws at all. But this would cast no suspicion on the contribution such parts of science may make to a unified science. On our proposal, the unity of science is an ideal of the complete unity of our theoretical insights, an ideal that guides discovery of the laws of nature only when and where they exist.

We develop our argument as follows. In $\S 2$, we set ourselves up with a selective survey of the debate between unity and disunity views. Our positive view is laid out over the next two sections. $\S 3$ begins by accepting several epistemically motivated challenges to earlier conceptions of unity, and leveraging these insights to argue for a procedural conception of unity, which we call unified pluralism. If this section argues for conceiving of scientific practice as a unity, $\S 4$ turns the focus to what such a unified activity should be understood as aiming for. Extending the epistemic arguments that motivated unified pluralism thus leads to a more robust conception of the unity of science, understood as a

\footnotetext{
${ }^{2}$ Although we think that the account we articulate and defend is one that can be attributed to Kant, we do not here undertake the necessary exegetical work to defend such an interpretive claim or to situate our interpretation among others. We do provide some references to Kant to orient the interested reader.
} 
substantive ideal of a complete science. In our concluding section, $\S 5$, we return to the question of the relation between the unity of science and the unity of nature, considering how a conception of the unity of science grounded in epistemological concerns could nevertheless reveal something about nature and its ultimate lawful unity or lawless disunity.

\section{Two Conceptions of the Unity of Science and A Pluralist Response}

Consider, first, arguments that take the unity of science to be grounded in the unity of nature. A famous example of this view is set out in Paul Oppenheim and Hilary Putnam's influential 1958 paper, "The Unity of Science as a Working Hypothesis." What the authors envision by the 'unity of science' is an explicitly "unitary" theory: a complete account of everything in a single conceptual idiom that sets out a single set of laws $(1958,4)$. They regard the unity of science as a well-established empirical hypothesis, supported by evidence supplied by actual scientific practice (see 1958, 16-27), but grounded in and mirroring the unity of nature. On their view, science could be a reductive unity only if nature is also a unity, and a unity of a specific kind: higher-level entities must be mereological composites of micro-level entities, fully explained by laws of the micro-level. Thus in Oppenheim and Putnam's view, the reductive unity of science reflects and reveals the uniform, homogeneous, and thoroughly lawful character of nature.

Few now accept the Oppenheim and Putnam conception of the unity of science, which we will refer to as the 'classic' view. ${ }^{3}$ John Dupré (1993), for instance, argues that the failure of several prominent reductionist projects - the attempt to explain ontogenetic processes in terms of molecular genetics, or to eliminate folk-psychological laws in favor of

\footnotetext{
${ }^{3}$ A significant attack was famously raised by Putnam himself with his $(1975,292-303$ and 429-40) arguments that the multiple realizability of functional states forecloses on reductionist ambitions. See also Fodor (1974).
} 
neurophysiological laws - provides a significant body of empirical evidence against the classic unity thesis (see also Cartwright 1999 and Waters 2016). The weight of empirical evidence, Dupré argues, reveals the sciences to be a motley, disunified group; and the disunity of science can in turn be taken to reflect a disorder and disunity in nature itself. Nature now appears as a heterogeneous plurality of entities, governed, if at all, by an irreducible plurality of laws - a far cry from the minimalist order envisaged by Oppenheim and Putnam.

How conclusive are these arguments? How conclusive could such arguments be? As Dupré himself notes, "no amount of . . . evidence can rule out the possibility that [the] diversity [of science] reveals only the immaturity of most of science" (1996a, 102; also 1996b; Cartwright 1999, 12; Mitchell 2003, 184). We agree with the parties to this debate that the structure of science reflects the structure of nature in some way, to some degree. This seems to follow from even a moderately realist conception of science. But, as the following sections show, we are less convinced by the thought that the structure of our best science is revealed by purely empirical considerations. We thus turn to a second kind of argument, which grounds the unity of science in epistemological considerations.

A well-known epistemologically motivated defense of the unity of science is found in the work of Michael Friedman and Philip Kitcher. ${ }^{4}$ Though primarily concerned to offer an account of scientific explanation, Friedman and Kitcher articulate an influential conception of the unity of science that we will call the 'unificationist' view. According to this view, we

\footnotetext{
${ }^{4}$ Kitcher changes his view in later years. The main shift, according to Kitcher's own statement, is that he comes to reject the idea that science is engaged in a "grand project of articulating the most unified vision of nature that we could achieve" $(1999,347)$. He also comes to deny that systematic unification captures "the essence" of scientific understanding (2001, 71).
} 
gain scientific understanding by unifying: by reducing the number of independent phenomena that we simply accept as brute, further inexplicable givens (Friedman 1974, 15) or by minimizing the number of distinct explanatory patterns and schemata employed by our theory (Kitcher 1981, 515-19; 1989, 432-33; 1995, 171-73). ${ }^{5}$ Explanation is construed in terms of deductive derivation: we explain when we deduce some phenomenon from a unifying premise or by using an explanatory pattern from our unifying set. The premises most frequently averted to, whether immediately or via a chain of explanatory deductions, will be the most general, fundamental, and explanatory. They will, as Kitcher puts it, be the “statements accepted as laws" (1989, 447; see also Friedman 1974, 15f.).

By contrast with the classic conception, the unificationist thesis about the nature of explanation and understanding does not show that nature is necessarily a reductive, homogeneous unity. It also does not guarantee that we will be able to unify our theory to any particular degree, and thus attain any particular level of scientific understanding. But the unificationist thesis is, in a different sense, reductionist: the quest for understanding is the quest to reduce the number of independent explanatory principles in our deductive system, and thus to reduce the number of laws that must be posited.

The unificationist account, like the classic view, has faced a number of challenges. We focus on two that are of particular importance for our purposes. According to the first, the unificationist view is saddled with too narrow a conception of unification and thus too narrow a conception of understanding. Friedman and Kitcher admit only one route to increasing

\footnotetext{
${ }^{5}$ This is an oversimplified characterization; we can also, for instance, effect a unification by increasing the number of phenomena explained while holding fixed or even increasing the number of fundamental principles. Many challenges to the unificationist project question whether the notion of unification can be made sufficiently precise. We focus our attention elsewhere, but see, e.g., Humphreys (1993).
} 
understanding: unifying, understood as finding ways to deduce more from less. However, not all unification takes this form, and not all understanding involves such unification. ${ }^{6}$ For example, we might come to see why two different theories, though not subsumable under a single more general theory, can nevertheless be consistently held together because they carve out phenomena in equally illuminating but irreducible ways. In such cases, we might gain understanding and unify theories by increasing rather than reducing our store of fundamental premises or explanatory patterns. ${ }^{7}$

A second objection, related to the first, is the following. Since, according to Friedman and Kitcher, understanding is only achieved by unification and theories can only be unified as a whole, we can only increase our understanding of nature as a whole - globally, never locally. As Friedman puts it, when we unify, "our over-all understanding of the world is increased" $(1974,18)$. But this conception of understanding is also too restrictive. It seems that we can gain understanding of specific particulars, and of the relation between a few theories, before we even attempt global unification. Sandra Mitchell $(2003,194)$ offers the following, intuitively compelling example. If we want to explain a complex particular such as the ecosystem of Lake Erie, what better way than to proceed by drawing on the resources, methods, and insights of various relevant scientific fields only as necessary? Such ad hoc integration provides us with local, highly specific understanding that satisfies our scientific aims without either requiring or yielding global integration and understanding. We think

\footnotetext{
${ }^{6}$ This point is emphasized in Morrison (1994).

${ }^{7}$ Although it remains a controversial question, one might also think that biology relies on two irreducible kinds of explanation, causal and functional. On the relevance of the Kantian position to this question, see Breitenbach (2009a).
} 
Mitchell is right: we can achieve deeper understanding at the local level without necessarily effecting a reductive unification in our overarching theory. ${ }^{8}$

These epistemically motivated objections to unificationism are representative of a more general challenge that applies to both the conceptions of the unity of science discussed here. It is a challenge expressed, for example, by Nancy Cartwright, when she warns that the hankering for unity is a scientific liability that might tempt us, for instance, to award "additional credibility" to some theory just because it has more systematic or foundationalist ambitions, not because it is better supported by the available evidence (1999, 12-18). More generally, Hasok Chang argues that even if nature is a perfect unity that can be grasped by a single science, we are unlikely to hit upon such an all-encompassing scientific framework. We are thus better off exploring and developing multiple frameworks (2012, 255-58). If these philosophers are right, then even if science can in the end be unified, we should not strive for such unification.

Many philosophers of science, especially those working in philosophy of biology, have been persuaded by this line of thought. Thus one finds announcements of an emerging "consensus" embracing the pluralism or disunity of science (Mitchell 2003, 180; Brigandt 2010, 296). A broad and heterogeneous alliance of theories can be found under this pluralist banner. According to ontological pluralism, for example, no room remains for the classic reductionist conception of nature as consisting of nothing but fundamental micro-particles and their governing laws; instead, we have a welter of kinds upon kinds, with no single hierarchy in which to regiment them and causal properties thus emerging at various levels of

\footnotetext{
${ }^{8}$ An important caveat: pace Mitchell, we think that the success of such local unification hints at the presence of more general and global insights in the vicinity, and to this degree, our understanding is increased as a whole. We discuss this further in $\S 4$. For a related challenge to Friedman and Kitcher, see $\operatorname{Kim}(1989,65)$.
} 
organization (e.g., Dupré 1993; cf. Waters 2016). According to explanatory pluralism, moreover, the deductive model of explanation lying at the heart of both the classic and unificationist views is marginalized, and with it goes a central reason for taking scientific laws and their discovery to be of such paramount importance. This is especially true in biology: biological explanations only rarely take deductive-nomological form; other kinds of explanation, such as mechanistic explanation, are not only prevalent but undeniably explanatory (e.g., Machamer et al. 2000; Brigandt 2013). Pluralists further point to the ubiquity of multiple representational systems and conceptual schemes, which posit different and sometimes cross-cutting levels of organization (e.g., Love 2012; Mitchell and Dietrich 2006), and the variety of interests, aims and methodological and experimental approaches found among practicing scientists and thriving research programs (e.g., Chang 2012 and Mitchell 2003). Though the arguments given in defense of pluralism vary, ranging, like their counterpart arguments for unity, from metaphysical to epistemological, they all point to the value of letting the proverbial hundred flowers bloom.

We are attracted to the inclusiveness of this approach, but we believe that there remains much to recommend, even necessitate, conceiving of science as a unity. We defend this claim over the next two sections. We propose a third conception of the unity of science, one that builds on several pluralist arguments and thus avoids the difficulties that dogged the classic and unificationist conceptions of the unity of science, while inheriting many of the strengths of pluralism.

\section{Unified Pluralism}

The conception of the unity of science that we will defend is, like the unificationist view and a subset of pluralist views, motivated by epistemic concerns. We set out our view in two steps. In this section, we leverage the kinds of epistemic reflections, often adduced to defend 
pluralism, to support what we call 'unified pluralism', a procedural unity of science that embraces pluralism but adds a unity requirement. We argue that this unity requirement is necessary to make an epistemic virtue out of proceeding pluralistically. Thus this conception of the unity of science focuses on the activity or practice of science. In the next section, we extend the arguments of this section further to argue for a thicker conception of the unity of science as a body of knowledge. ${ }^{9}$

Our argument for unified pluralism commences with a claim that, though distinctively Kantian, is uncontroversial enough. To put it simply: our epistemic capacities are limited. Even when wielded with astonishing power and ingenuity by the likes of Newton and Einstein, our epistemic abilities fall short of our epistemic ambitions. What follows? According to Chang, a recognition of our epistemic limits should engender a sober "humility," for "we are limited beings trying to understand and engage with an external reality that seems vastly complex, apparently inexhaustible, and ultimately unpredictable." Such humility, in turn, provides Chang with the "most fundamental motivation" for his kind of pluralism (2012, 255; also 292-94). But whereas Chang takes epistemic humility to drive us to a pluralism that remains in principle against the unity of science, Kant takes such humility to generate a need for the unity of science. That Kant's arguments for the necessity of the unity of science are found in the same section of the Critique of Pure Reason devoted to exposing our epistemic limitations is no accident. ${ }^{10}$ It is this Kantian intuition that we aim to spell out here. ${ }^{11}$

\footnotetext{
${ }^{9}$ Though we draw a distinction here between the practice and the product of science, we do not think the distinction is a hard and fast one. What counts as an adequate explanation, appropriate methodology, or good evidence is hardly theory-neutral.

${ }^{10}$ See A642-704/B670-732. References to the first Critique use the original pagination, with A and B referring to the first (1781) and second (1787) edition, respectively. All other
} 
So where does the Kantian line of thought part ways with the pluralist argument? Pluralists driven by epistemic considerations_-Chang, but also several others - have offered illuminating analyses of our epistemic limitations and capacities, and argued that pluralism is the way to make the most of the former in light of the latter. To take just one subset of such arguments, consider defenses of explanatory pluralism. Explanatory pluralists join in the chorus of challenges to deductive-nomological explanations; such explanations, they say, are neither the only nor the best game in town. There are many areas of scientific inquiry in which we have not formulated any general laws and so cannot give deductive-nomological explanations, but are nevertheless able to provide sophisticated explanations that satisfy our aims (e.g., Bechtel and Abrahamsen 2005; Brigandt 2010; Mitchell 2003). And even when deductive-nomological explanations are available, they may not be what we want. As Putnam famously notes, the prosaic fact that cubical pegs of a certain size will pass through square holes of a certain size but not round holes of a certain size is not satisfactorily explained by giving a complex deduction of it from microphysical properties (Putnam 1975, 295f.). Though many philosophers would agree with these challenges to the deductive-nomological account of explanation, explanatory pluralism goes further. It would be unsurprising, the pluralist thinks, if there are many different kinds of explanation that are equally good, appropriate to and sufficient for the variety of our actual scientific aims and the nature of our cognitive capacities. There is certainly no need, the pluralist concludes, to look for a monolithic account of explanation or to search for a universal framework within which the

references to Kant are to the volume and page numbers of the Akademie edition (Kant 1900ff.); translations are our own.

${ }^{11}$ Our interpretation of Kant here is strongly indebted to O’Neill (1989, 3-27; 1992). 
values and roles of different kinds of explanations can be situated (e.g., Brigandt 2010; Kellert et al. 2006, xxvi; Love 2012). ${ }^{12}$

This example presents one way, among several, in which pluralists take reflections on our epistemic limitations and capacities to lead to the conclusion that we should embrace pluralism. ${ }^{13}$ We agree with these arguments — so far as they go. It seems that the right response to a clear-eyed recognition of our epistemic situation is to engage in the active pursuit of many different kinds of inquiry and the active recruitment of many different inquirers. We thereby maximize the use of our cognitive capacities; we thereby also provide checks and correctives for ourselves, since others can compensate for the natural blindspot that makes it harder for us to spy out weaknesses in our own views. Thus we agree with pluralists who urge that we have epistemic reason to adopt a range of methodological

${ }^{12}$ Though Kant himself uses 'explanation' [Erklärung] narrowly_it must involve deduction from a general principle (Kritik der Urteilskraft [KU] 5:412) — he introduces a wide variety of activities that are explanatory in a broader sense: conceptualization, which Kant calls "understanding" [Verstehen] (Jäsche Logik [JL] 9:64-5); systematic classification, which Kant calls "description of nature" [Naturbeschreibung] (KU 5:417; Metaphysische Anfangsgründe der Naturwissenschaft 4:471); and systematic analysis, which Kant calls “exposition” [Exposition] (JL 9:142-3; KU 5:412); among others. Insofar as he takes these cognitive activities to be necessary to and ineliminable from science, Kant can be considered an explanatory pluralist.

${ }^{13}$ For examples of epistemically motivated arguments for pluralism about representational systems, see Mitchell (2003); for arguments to pluralism about competing theories, see Mitchell and Dietrich (2006); for pluralism about scientific aims and values, see Longino (2002a and 2002b). Chang (2012) and Kellert et al. (2006) argue for all these kinds of pluralism. 
approaches, be ecumenical about scientific explanations, support the development of a wide variety of competing theories, and embrace multiple conceptual schemes and classificatory systems.

But we think it is not enough just to advocate pluralism. We cannot stop there. To see why, consider the following. Say two individuals are trying to solve a difficult, novel problem. Is it better for our two individuals to take two different approaches and test two different hypotheses than for them to take the same approach and test the same answer? No, or at least, not necessarily! It might make no difference at all. For if the individuals are not aware of each other, or if they are uncommunicative and uncooperative with each other, there is no benefit to be gained at all from adopting different approaches. Adopting different approaches is beneficial only if the individuals are communicating and cooperating enough that it can be said that they are together trying to solve the problem using a plurality of approaches. How does this simple thought extend to our central concerns?

We have taken the pluralist to insist that many different ways of proceeding in our scientific pursuits are good. ${ }^{14}$ And we have agreed with the pluralist about this. However, as stated, the view is ambiguous. On one reading, the claim would say that it is good for me that I pursue theory A and good for you that you pursue theory B. This amounts to a form of relativist pluralism: there are many goods, but goodness is position-relative. On another reading, the claim would say that it is good for $u s$ that I pursue theory A and that you pursue theory B. This amounts to a unified pluralism, and it is the kind that we endorse: there are

\footnotetext{
${ }^{14}$ Contrast this with the alternative claim that, although only those ways of proceeding that will turn out to be successful are good, we should nevertheless proceed pluralistically because we do not know which ways of proceeding are good. Such a view defends pluralism only insofar as it is a necessary means to a desired end. We think many pluralists deny this; so do we.
} 
many goods, and that there are many goods is good for each of us. Unified pluralism insists that participants are together, collectively engaged in an activity. ${ }^{15}$ We endorse this second form of pluralism because pursuing a wide variety of means is only an epistemic boon if we are all together engaged in an activity. If we are not, there is no epistemic value to pluralism. For pluralism to be a response to our epistemic limitations it has to be a unified pluralism. ${ }^{16}$

What, though, does unified pluralism concretely entail? Does it amount to a view that is substantively different from other kinds of pluralism? We think so. Unified pluralism embraces a wide range of pluralisms but imposes one important, governing limitation: it rules out ways of proceeding that undermine the continued cooperation and collaboration necessary to make a virtue out of pluralism. Unified pluralism thus excludes only but all exclusionary projects. A few kinds of projects are necessarily ruled out, such as the elaboration of conspiracy theories, which transmute any evidence against them into evidence

\footnotetext{
${ }^{15}$ We take it to be possible for scientists to be collectively engaged in the project of scientific inquiry even if they have very different aims. Some may have the staunchly realist aim of getting at the truth; others may aim at reliable prediction, problem-solving, or empirical adequacy; but all may be part of a larger collective effort to investigate nature--and they may see themselves as such. We take a similar sentiment to be expressed in Chang: "what we want science to do is to give us an account of the natural world that serves whatever ultimate aims we may have" $(2012,260)$. Our singular 'activity' is meant to be no more monist than Chang's singular 'account'.

${ }^{16}$ We do not mean to imply that all pluralists espouse a relativist pluralism; in fact, some explicitly distinguish their views from relativism (e.g., Chang 2012, 261-64; Dupré 1993, 261f.). For the pluralists who agree with us, we think that it is therefore just as important to emphasize the collective, collaborative element as it is to articulate the commitment to pluralism.
} 
for them by taking them to reveal the widespread nature of the conspiracy. There is no cooperation or collaboration with a conspiracy theorist. Other projects are ruled out sometimes, under certain circumstances or when pursued in a certain manner. For instance, the classic reductionist project might seem to be necessarily exclusionary, because it takes certain scientific disciplines to be redundant and works toward their elimination. But the reductionist who allows, for instance, that the success or failure of her project can be judged by those who reject the reductionist view, especially those whose theories are said to be reducible without loss of information, proceeds in a way that is in fact compatible with nonreductionist projects. This kind of reductionist project can be pursued as part of a pluralist science. It is when the reductionist regards the criteria of success for her project to be determined entirely within the reductionist enterprise, however, that her way of proceeding is exclusionary and incompatible with a collaborative science. Thus sometimes, whether a project is exclusionary or not depends on how it is conceived and carried out. But sometimes, projects turn out to be exclusionary for entirely external reasons: highly expensive projects, for instance, that can only be carried out at the cost of others, should sometimes be excluded. And it will generally be the case that we should take care not to let a particular project dominate, though there may be special circumstances when scarcity or urgency makes it necessary to take the epistemic risk and devote all our resources in a particular project.

We have thus far argued that pluralism has the epistemic virtues it claims only within a collaborative science, and that a collaborative science is sustained by excluding all exclusionary projects. According to unified pluralism, scientists ought to proceed as collaboratively and cooperatively as is necessary to make an epistemic virtue out of proceeding pluralistically. As the above examples show, our overarching unifying requirement is consistent with a broadly pluralist approach. It leaves room for the possibility that scientists should continue to work on radically different projects, developing 
independent, perhaps even incompatible, theories and explanations. Importantly, we have not defended unified pluralism as a means to any final unified science. Adopting unified pluralism does not guarantee that our scientific endeavors will yield a single unified theory or a unified set of laws. But the considerations that have led us this far give us good grounds for going further and endorsing a more robust conception of the unity of science. This is what we argue in the next section.

\section{Pluralist Unity of Science}

In the last section, we argued that we reap the advantages of pluralism only if we treat scientific practice as a collaborative venture — only if we embrace unified pluralism. In this section, we add that the epistemic reasons for adopting our thin conception of procedural unity extend further, to recommend a thicker conception of unity. Procedural unity concerns how we should engage in our scientific practices, regardless of what we want to achieve. But is there not something that we hope to achieve? If scientists proceed as they should, exploring the world in wide-ranging, imaginative and diverse, but cooperative and collaborative, ways, and if the world turns out to be tractable, then is there not some ideal lurking there of what we could, in the best case scenario, achieve? We think that there is, and that there is reason to make this a regulative ideal, one that governs our scientific activities and practices. In this section, we first characterize this ideal, which we call the 'pluralist unity of science'; and we offer arguments in support of it. We conclude by explaining how adopting this thicker conception of the unity of science as a regulative ideal generates more substantive demands on scientific practice than the weaker procedural conception of unified pluralism does.

We can begin to conceptualize this ideal by considering how the various scientific theories generated by proceeding in a unified but pluralist manner might, at the end of inquiry, come together. In the best case scenario, if the world proves hospitable to our 
scientific aims, this final science would do more than make every part of the world independently understandable to us. It would make the world understandable to us as a whole. ${ }^{17}$ Thus this ideal science could not be an aggregate of theories, a list of conceptual schemes, a heap of unrelated explanations. It would have to be a systematic ordering of our theories, conceptual schemes, and explanations, one that allows us to grasp them together, as a whole - and one that thereby allows us to understand nature itself as a whole. ${ }^{18}$ In other words, this ideal science would have to be a maximally complete and fully integrated unity.

This conception of the unity of science amounts to the articulation of an epistemic ideal. It is positively characterized by its ideal epistemic properties: its completeness, its systematicity, its unity. But it remains indeterminate in other ways. For example, it is neither

${ }^{17}$ Kant sometimes presents this idea as that of the "purposiveness of nature" [Zweckmäßigkeit der Natur] for our understanding (KU 5:181). On this idea, see Breitenbach $(2009 ; 2017)$.

${ }^{18}$ Kant himself sometimes talks of mere aggregates as unities, but in order to argue that such unities are not systematic unities and thus lack epistemic significance (A645/B673). We use 'unity' only to refer to Kant's systematic unities - those unities that are epistemically significant. Kant also sometimes characterizes the kind of systematic unity that we describe above as a "collective" rather than "distributive" unity (A644/B672; Prolegomena 4:328). Distributive unity is the unity of many-under-one, the unity possessed, for instance, by an otherwise motley assortment of red things. Collective unity is a unity in which diverse parts stand in a determinate relation to one another in accordance with a single idea of the whole. On the Kantian account, such a collective "first makes ordinary cognition into science, i.e., makes a system out of a mere aggregate of cognitions" (A832/B680). See Breitenbach (forthcoming) for a more detailed account. 
reductionist nor non-reductionist. ${ }^{19}$ We simply do not know in advance of inquiry whether particular natural phenomena can be explained in a single theoretical framework or whether they must be explained by a plurality of irreducible theoretical accounts. We have to wait for nature to tell us. ${ }^{20}$ In particular, ideal science need not necessarily take the form of the classic reductionist's unitary theory of everything, or the unificationist's deductive system in which a few laws or argument-schemas entail a huge number of phenomena. Ideal science could take one of those forms, but it could also turn out to be a unity constituted of heterogeneous parts: many different scientific theories, with distinct aims, methodologies, explanatory forms, and representational and classificatory systems. In such a case, however, each of these parts would have to, in virtue of its heterogeneity, play a unique, necessary and specifiable role in contributing to our unified understanding. The mere conjunction of theories would not generate the kind of understanding characteristic of this ideal unity of science.

No matter what specific structure this unity takes, it would be effected by proceeding in a pluralist fashion. This is why we call it a pluralist unity of science. But proceeding in accordance with unified pluralism does not yet amount to aiming for the ideal pluralist unity of science. Recall that unified pluralism demands that each scientist proceed in a way that preserves the ongoing possibility of science as a collective endeavor. Aiming at the ideal pluralist unity of science generates further specific demands that outstrip the more minimalist requirements of unified pluralism. As we suggested, the pluralist unity of science is the ideal science that would emerge by integrating the plurality of theories generated by the scientific community as a whole. Adopting this idea of unity as a regulative ideal therefore requires taking ongoing scientific inquiry to contribute to a single understanding of the world. More specifically, it gives us a standing reason to engage in a range of unifying activities: for

\footnotetext{
${ }^{19}$ For Kant's version of this, see A663/B691 and A680/B708.

${ }^{20}$ For Kant's version of this, see A654/B682.
} 
instance, looking for encompassing frameworks within which different explanations can be seen to be compatible, trying to integrate different theories, but also accounting for why two incompatible theories are irreducible but necessary. Furthermore, because the ideal leaves the precise structure of the unity of science open, leaving it a matter to be determined by empirical inquiry, it actively guides inquiry into competing possibilities and thus encourages pluralism. We have reason to look into the uniformity of different phenomena and the reducibility of their theoretical accounts, but we also have reason to capture the fundamental diversity of the phenomena and the essential irreducibility of their explanations. ${ }^{21}$

Of course, as a matter of fact, we can never exhaustively explore these competing possibilities. We may very well never achieve a complete unification of all scientific theories and a perfect understanding of how different theoretical frameworks relate. But even if the sciences remain thoroughly disunified, even isolated, and even if we have reason to think that the ideal unified science is unachievable, it does not follow that we cannot or should not aim for it. ${ }^{22}$

But why then should we aim for it? Why ought we strive for a concrete understanding of how different theories and explanations relate to each other and contribute to an understanding of nature as a whole? Here we seek to address someone who concedes that our conception of the ideal unity of science spells out a best-case scenario, but denies that we

${ }^{21}$ For the Kantian version, see his claim that the ideal of unity brings with it three subordinate maxims, the principles of homogeneity, specification, and affinity (see A657f./B685f.).

${ }^{22}$ Thus the ideal unity of science is ideal in a dual sense: it is a mere ideal, because we will never attain it, but it is still an epistemic ideal that guides us, conceptualizing our own understanding of what our scientific activities would achieve if we were not limited as we are. 
should adopt it as a regulative ideal governing inquiry. Such a person might argue that we have enough scientific aims and goals to guide inquiry in fruitful directions, and do not need a further, distant goal to orient us. More forcefully, such a person might argue that we must not be dazzled by such distant ideals, since they may distract us from our more immediate concerns and pull us away from our most pressing problems.

In response, we first note that, just by satisfying the demands of unified pluralism, we go some way to satisfying the demands of the richer ideal pluralist unity. Unified pluralism asks that we do what is necessary so as to maintain the conditions under which pluralism can be an epistemic benefit. But this will often require determining whether two apparently competing theories are indeed inconsistent with each other, or whether apparent inconsistencies can be accounted for by legitimate differences in aims or conceptual schemes, or whether the two theories are irreducibly distinct but complementary, offering pieces of a larger story. Thus satisfying the demands of unified pluralism may often suffice to satisfy the demands of the richer, ideal conception of unity.

But even when this is not the case, there are epistemic reasons to pursue ideal unity. We return again to Mitchell's example of trying to understand the ecosystem of Lake Erie. Lake Erie is a highly complex particular, composed not only of a mix of multicellular organisms, single cells and molecules, but also determined by such factors as climate and geology. ${ }^{23}$ In order to get to grips with this complexity, we need to understand not only how molecular biology explains some features of the lake, and geology some others, but also how the molecular and geological explanations interact. We thus gain epistemic benefits by seeking a positive understanding of how the two theories relate to one another. Mitchell argues that such integration not only can but should stop at the local level; it is appropriate just when and if a specific scientific question arises that calls for it (Mitchell 2003; also

\footnotetext{
${ }^{23}$ On the irreducible complexity of ecosystems, see Dupré (1993, 107-20).
} 
Brigandt 2010). Thus Mitchell denies that we ought to generalize after effecting local integration; we have, in her view, no epistemic reason to pursue it. But we think that if local integration is desirable in some cases, then why not aim for more? Would not the same rationale for the integration of different viewpoints hold at any level of inquiry? We see no principled reason to regard the question about the relation between two different theories or explanations as legitimate in one case, and illegitimate in another. Of course, just because there is an epistemic reason to pursue further integration does not mean that, all things considered, we should pursue further integration. There might be more pressing things to attend to. Nevertheless, the point we want to urge is that the epistemic benefits are there to be reaped, and that further integration should be considered a legitimate venture and desirable result at any point of inquiry.

These kinds of epistemic considerations, we believe, point to a more fundamental concern that motivates the move from unified pluralism to the pluralist unity of science. The thought is that it is intellectually unsatisfactory to see ourselves as participants engaged in a collaborative project without asking further questions about how the different parts of this project contribute in their different ways to our collective endeavor. Imagine again our two individuals trying together to solve a problem by pursuing different means. They may without contradiction choose simply to work on their own projects, minimally united in virtue of investigating a common problem. But proceeding in this way will always leave certain questions unanswered. Is one theory better than the other, and if so why? Or are both proposed solutions true of the phenomena, and if so how can they both be right? Are they both partial but mutually complementary parts of the solution? Or are they incompatible but enlightening in different ways and, if so, how could this be? Do they, for example, abstract from the phenomena in different respects and thus pick out only partially overlapping kinds of entities? For the scientists' collaborative effort to be fruitful, and to generate a satisfactory 
answer to these further questions, scientists will need to have an understanding of how their different projects relate, for instance, by subsuming them under one more general framework or by getting a better grip on the relation between mutually irreducible theories and explanations.

Aiming to unify our theoretical insights in this way thus constitutes an aim beyond unified pluralism. In regarding a plurality of research projects, and of resulting theories and explanations, as possible contributions to a common effort, we assume that they contribute to the understanding and insight we can achieve together. We assume the results of different inquiries can be compared and contrasted with one another in order to add to a better understanding of the same natural world, understanding that, if it could be completed, would be an understanding of the natural world as a whole. Aiming to unify our theoretical insights in this way is, we suggest, what it means to regard the pluralist unity of science as a regulative ideal.

\section{Conclusion}

We have proposed a conception of the unity of science that is driven by epistemological concerns. The ideal of the unity of science we propose draws on many of the concerns that motivated the pluralist opposition to both the classic and unificationist conceptions of unity. It thereby sidesteps some of the problems that plagued these other unity views, and converges with the pluralist view in significant ways. But pace the pluralists, we argue that an underlying commitment to unity should govern pluralist scientific activity; and pace the classic and unificationist views, we argue that the ideal science we aim for can be understood as a non-reductionist unity.

We close by returning to an issue raised in our introduction. We noted there that arguments for the unity or disunity of science often entail something about the unity or 
disunity of nature. For instance, on the classic and unificationist pictures, scientific theories are deductive systems, unified by a set of fundamental principles from which all other phenomena can be deduced and thus explained. Conceiving of the unity of science in this way entails that to engage in scientific activity is to engage in the search for these fundamental principles. That is, the defining aim of science turns out to be the identification of the laws of nature - a view that has been challenged, rightfully, in our opinion, for its myopia, for leaving out more than it accounts for. On the pluralist view, the importance of discovering laws of nature recedes along with the reliance on the deductive-nomological model of explanation. The fact that it is unclear whether there are any laws in biology, for example, casts doubt not on the scientific bona fides of biology, but on the assumption that a central aim of science is the articulation of laws.

What about on our view? What, if anything, does our conception of the unity of science entail about the lawfulness or lawlessness of nature? On our proposal, the particular form that the unity of science will take is left open, ultimately to be determined by the results of empirical inquiry. In being guided by the ideal of pluralist unity, we may discover a set of fundamental laws reigning universally throughout; but alternatively, we may find ourselves with a picture of nature as partially governed by irreducible laws. Unity is thus not wedded to simplicity and fundamentality but tracks a broader notion of completeness and comprehensibility. Although it cannot guarantee the discovery of a single set of universal laws, it makes possible the discovery of the laws of nature as there are. ${ }^{24}$

\footnotetext{
${ }^{24}$ We thank Alix Cohen and Michela Massimi for very helpful comments on earlier versions of the paper, and the audience at the Higher Seminar for History of Philosophy, Uppsala University, where this paper was presented, for stimulating discussion. Angela Breitenbach gratefully acknowledges the support of the Riksbankens Jubileumsfond and the Swedish Collegium for Advanced Study.
} 
Angela Breitenbach

Faculty of Philosophy

University of Cambridge

Cambridge CB3 9DA

UK

ab335@cam.ac.uk

Yoon Choi

Marquette Hall 115

PO Box 1881

Marquette University

Milwaukee, WI 53201-1881

USA

yoon.choi@marquette.edu

References

Bechtel, William and Adele Abrahamsen 2005. "Explanation: A Mechanist Alternative," Studies in History and Philosophy of Biological and Biomedical Sciences 36: 421-41.

Breitenbach, Angela 2009a. "Teleology in Biology: A Kantian Approach,” Kant Yearbook 1: $31-56$

—. 2009b. Die Analogie von Vernunft und Natur, Berlin/New York: de Gruyter.

_ 2017. "Laws in Biology and the Unity of Nature," in Massimi and Breitenbach, eds. (2017: 237-255). 
—. forthcoming. "Laws and Ideal Unity," in Ott and Patton, eds.

Brigandt, Ingo 2010. "Beyond Reduction and Pluralism: Toward an Epistemology of Explanatory Integration in Biology,” Erkenntnis 73: 295-311.

—. 2013. "Explanation in Biology: Reduction, Pluralism, and Explanatory Aims," Science and Education 22: 69-91.

Cartwright, Nancy 1999. The Dappled World: A Study of the Boundaries of Science, Cambridge: Cambridge University Press.

Chang, Hasok 2012. Is Water H2O? Evidence, Pluralism and Realism, Dordrecht: Springer. Dupré, John 1993. The Disorder of Things: Metaphysical Foundations of the Disunity of Science, Cambridge, MA: Harvard University Press.

—. 1996a. "Metaphysical Disorder and Scientific Disunity," in Galison and Stump, eds. (1996: 101-17).

_ 1996b. "Promiscuous Realism: Reply to Wilson," British Journal for the Philosophy of Science 47: 441-44.

Fodor, Jerry 1974. "Special Sciences (Or the Disunity of Science as a Working Hypothesis)," Synthese 28: 97-115.

Friedman, Michael 1974. "Explanation and Scientific Understanding," Journal of Philosophy 71: 5-19.

Galison, Peter and David J. Stump, eds. 1996. The Disunity of Science: Boundaries, Context and Power, Stanford: Stanford University Press.

Guyer, Paul, ed. 1992. The Cambridge Companion to Kant, Cambridge: Cambridge University Press.

Humphreys, Paul 1993. “Greater Unification Equals Greater Understanding?,” Analysis 53: $183-88$.

Kant, Immanuel 1900ff. Kants Werke, Berlin: Preußische Akademie der Wissenschaften. 
1998. Kritik der reinen Vernunft, ed. J. Timmermann, Hamburg: Felix Meiner.

Kellert, Stephen H., Helen E. Longino, and C. Kenneth Waters 2006. "Introduction: The Pluralist Stance," in their, eds. (2006: vii-xxix).

. eds. 2006. Scientific Pluralism, Minneapolis: University of Minnesota Press.

Kim, Jaegwon 1989. "Mechanism, Purpose, and Explanatory Exclusion," Philosophical Perspectives 3: 77-108.

Kitcher, Philip 1981. "Explanatory Unification,” Philosophy of Science 48: 507-531.

- 1989. "Explanatory Unification and the Causal Structure of the World," in Kitcher and Salmon, eds. (1989: 410-505).

- 1995. The Advancement of Science: Science without Legend, Objectivity Without Illusions, Oxford: Oxford University Press.

_. 1999. "Unification as a Regulative Ideal," Perspectives on Science 7: 337-348.

—. 2001. Science, Truth, and Democracy, Oxford: Oxford University Press.

Kitcher, Philip and Wesley Salmon, eds. 1989. Scientific Explanation, Minneapolis:

University of Minnesota Press.

Longino, Helen 2002a. "Reply to Philip Kitcher,” Philosophy of Science 69: 573-77.

- 2002b. "Science and the Common Good: Thoughts on Philip Kitcher's Science, Truth, and Democracy," Philosophy of Science 69: 560-68.

Love, Alan 2012. "Hierarchy, Causation and Explanation: Ubiquity, Locality and Pluralism," Interface Focus 2: 115-25.

Machamer, Peter, Lindley Darden, Carl F. Craver 2000. "Thinking about Mechanisms," Philosophy of Science 67: 1-25.

Massimi, Michela and Angela Breitenbach 2017. Kant and the Laws of Nature, Cambridge: Cambridge University Press. 
Mitchell, Sandra 2003. Biological Complexity and Integrative Pluralism, Cambridge: Cambridge University Press.

Mitchell, Sandra and Michael R. Dietrich 2006. "Integration Without Unification: An Argument for Pluralism in the Biological Sciences," American Naturalist: Supplement 168: 73-79.

Morrison, Margaret 1994. Unifying Scientific Theories: Physical Concepts and Mathematical Structures, Cambridge: Cambridge University Press.

O’Neill, Onora 1989. Constructions of Reason, Cambridge, Cambridge University Press.

—. 1992. "Vindicating Reason," in Guyer, ed. (1992, 280-308).

Oppenheim, Paul and Putnam, Hilary 1958. "The Unity of Science as a Working Hypothesis," Minnesota Studies in the Philosophy of Science 2: 3-36.

Ott, Walter and Lydia Patton forthcoming. Laws of Nature, Oxford: Oxford University Press. Putnam, Hilary 1975. Mind, Language and Reality: Philosophical Papers, Vol. 2, Cambridge: Cambridge University Press.

Slater, Matthew and Zanja Yudell, eds. 2016. Metaphysics in Philosophy of Science, Oxford: Oxford University Press.

Waters, C. Kenneth 2016. "No General Structure," in Slater and Yudell, eds. (2016: 81-108). 